\title{
High resolution profiling of human exon methylation by liquid hybridization capture-based bisulfite sequencing
}

Junwen Wang ${ }^{\dagger}$, Hui Jiang ${ }^{\dagger}$, Guanyu Ji ${ }^{\dagger}$, Fei Gao, Mingzhi Wu, Jihua Sun, Huijuan Luo, Jinghua Wu, Renhua Wu and Xiuqing Zhang*

\begin{abstract}
Background: DNA methylation plays important roles in gene regulation during both normal developmental and disease states. In the past decade, a number of methods have been developed and applied to characterize the genome-wide distribution of DNA methylation. Most of these methods endeavored to screen whole genome and turned to be enormously costly and time consuming for studies of the complex mammalian genome. Thus, they are not practical for researchers to study multiple clinical samples in biomarker research.

Results: Here, we display a novel strategy that relies on the selective capture of target regions by liquid hybridization followed by bisulfite conversion and deep sequencing, which is referred to as liquid hybridization capture-based bisulfite sequencing (LHC-BS). To estimate this method, we utilized about $2 \mu \mathrm{g}$ of native genomic DNA from YanHuang $(\mathrm{YH})$ whole blood samples and a mature dendritic cell (mDC) line, respectively, to evaluate their methylation statuses of target regions of exome. The results indicated that the LHC-BS system was able to cover more than $97 \%$ of the exome regions and detect their methylation statuses with acceptable allele dropouts. Most of the regions that couldn't provide accurate methylation information were distributed in chromosomes 6 and $Y$ because of multiple mapping to those regions. The accuracy of this strategy was evaluated by pair-wise comparisons using the results from whole genome bisulfite sequencing and validated by bisulfite specific PCR sequencing.
\end{abstract}

Conclusions: In the present study, we employed a liquid hybridisation capture system to enrich for exon regions and then combined with bisulfite sequencing to examine the methylation statuses for the first time. This technique is highly sensitive and flexible and can be applied to identify differentially methylated regions (DMRs) at specific genomic locations of interest, such as regulatory elements or promoters.

\section{Background}

The methylation of cytosines at $\mathrm{CpG}$ dinucleotides is an important regulatory modification in the somatic cells of mammals and other vertebrates $[1,2]$. It plays a vital role in regulating gene transcription during diverse biological processes, including embryonic development, X-chromosome inactivation, and the maintenance of pluripotency and chromosome stability [3-8]. Aberrant DNA methylation is associated with many common diseases. Recent evidence has demonstrated that the epigenetic

\footnotetext{
* Correspondence: zhangxq@genomics.org.cn

† Contributed equally

Beijing Genomics Institute at Shenzhen, Beishan Road, Shenzhen 518000, China
}

(c) 2011 Wang et al; licensee BioMed Central Ltd. This is an Open Access article distributed under the terms of the Creative Commons Attribution License (http://creativecommons.org/licenses/by/2.0), which permits unrestricted use, distribution, and reproduction in any medium, provided the original work is properly cited. DNA hypermethylation is involved in cancer development and progression [8,9]. Due to its relative genomic stability and well-established role in cancer pathogenesis, it is likely that DNA methylation is an important biomarker for the diagnosis and prognosis of certain diseases [10].

Understanding the exact role of DNA methylation in normal developmental and disease states requires knowledge of the distribution of methylation in the genome. Fortunately, reference genome assemblies and massively parallel sequencing enable the high-resolution genome-wide profiling of cytosine methylation. With this profiling, it is possible to identify methylation 
biomarkers in clinical samples using adequately powered epigenome-wide association studies.

There are three main types of strategies that are currently available for the high-resolution detection of DNA methylation based on the next generation sequencing platform. The first is whole genome bisulfite sequencing (WGBS), in which sodium bisulfite is applied to the genomic samples to convert all unmethylated cytosines to uracils. The uracil is subsequently recognized as thymine after PCR amplification [11,12]. This technique is the gold standard for cytosine methylation analysis in both $\mathrm{CpG}$ and non-CpG contexts because it allows for methylation detection at a single-base resolution $[11,12]$. However, whole genome sequencing is extremely time consuming and costly, especially when used to screen complex genomes. For this reason, it is impractical for the survey of multiple biological samples.

The second approach is based on the enrichment of methylated DNA fragments such as MeDIP-seq [13,14] and MBD-seq [15], which employ 5-methylcytosine-specific antibodies and methyl-binding domain proteins, respectively, to precipitate methylated fractions from a randomly sheared genomic DNA sample. Although these two methods are able to enrich fragments containing 5-methylcytosine, they screen the whole genome without representation and cannot determine the methylation statuses of individual CpGs within the fragments [13-18]. Even when combined with bisulfite conversion, these methods were still hampered by the enrichment bias that was caused by the CpGs densities and methylation statuses of the DNA fragments [16].

The third approach includes reduced representation bisulfite sequencing (RRBS) and bisulfite padlock probes (BSPP) [19-21]. RRBS digests genomic DNA with a specific restriction enzyme followed by bisulfite conversion and sequencing of the size-selected fractions $[19,20]$. This technique is able to cover multiple regions, including CpG islands, promoters and enhancer elements, and can yield data at a single-base resolution. It is a robust and relatively low-cost method but is limited to profiling the defined regions that correspond to the recognition sites of certain restriction enzymes $[17,18,20,22]$. Theoretically, BSPPs could be applied to detect any genomic region of interest by the design of specific probes. However, because they are involved in the hybridization of bisulfite-converted genomic DNA, each probe can only target a limited number of CpGs. This limitation hampers the flexibility of the probe design and applicability of this technology [21].

In the present study, we designed a novel strategy, termed liquid hybridization capture-based bisulfite sequencing (LHC-BS), which utilized biotinylated RNA probes to capture target regions of native genomic DNA by liquid hybridization platform and then followed by sodium bisulfite treatment and next-generation sequencing to survey the methylation statuses of specific genomic regions. Exome capture sequencing is a widely used technique to study diseases, and methylation status is gaining recognition as an important topic [23]. Here, we performed target (exome) capturing and parallel bisulfite sequencing to test the reliability of our platform. To validate the applicability of our approach, two types of samples were used: the YanHuang peripheral blood sample $(\mathrm{YH})$ and a mature dendritic cell $(\mathrm{mDC})$ line. Our results demonstrated that the current LHC-BS method was as effective as the bisulfite system in detecting methylation statuses of the captured regions. The technique provided the foundations for future highthroughput examinations of the methylation statuses of any genomic regions of interest.

\section{Result \\ Overview of LHC-BS}

The LHC-BS assay was based on a protocol that applied predesigned biotinylated RNA probes to capture target genomic regions of interest for further analysis. In the current study, we used the Agilent SureSelect Human All Exon Kit to enrich all human exons, which totalled approximately $38 \mathrm{Mb}$. The capturing was achieved using a liquid hybridization system that required only $2-3 \mu \mathrm{g}$ of genomic DNA for the library construction in contrast with the $20 \mu \mathrm{g}$ that is required for the array-based capture method $[24,25]$. To briefly summarize the experimental procedures, 2-3 $\mu \mathrm{g}$ of genomic DNA were randomly fragmented to mean sizes of approximately $250 \mathrm{bp}$. The manufacturer's protocols were followed for creating the blunt ends and for the $\mathrm{dA}$ additions to the 3 'ends and the methylcytosines modified adapter ligations. A total of $500 \mathrm{ng}$ of each adapter-ligated library $(147 \mathrm{ng} / \mu \mathrm{l})$ were denatured and hybridised with biotinylated RNA probes at $65^{\circ} \mathrm{C}$ for $24 \mathrm{~h}$. Then, Dynabeads ${ }^{\circledR}$ M-280 Streptavidin was used for the separation of target fragments, after which the captured beads were washed and the DNA fragments were eluted. After the fragments were treated with sodium bisulfite, PCR amplification was performed and the amplicons were sequenced using the Illumina/HiSeq 2000 (Figure 1).

\section{Data generation}

LHC-BS was successful in achieving sufficient coverage of the target regions based on a relatively small amount of sequencing. In this study, $88 \mathrm{M}$ and $132 \mathrm{M}$ raw reads were generated for the $\mathrm{YH}$ blood sample and $\mathrm{mDC}$ cell line, respectively (Additional File 1 Table S1). Of these reads, more than $75 \mathrm{M}$ and $106 \mathrm{M}$ reads were uniquely mapped back to the reference genome, giving unique map rates of $85.36 \%$ and $80.27 \%$, respectively. On average, the depths of coverage were $58 \times$ and $63 \times$ for the 


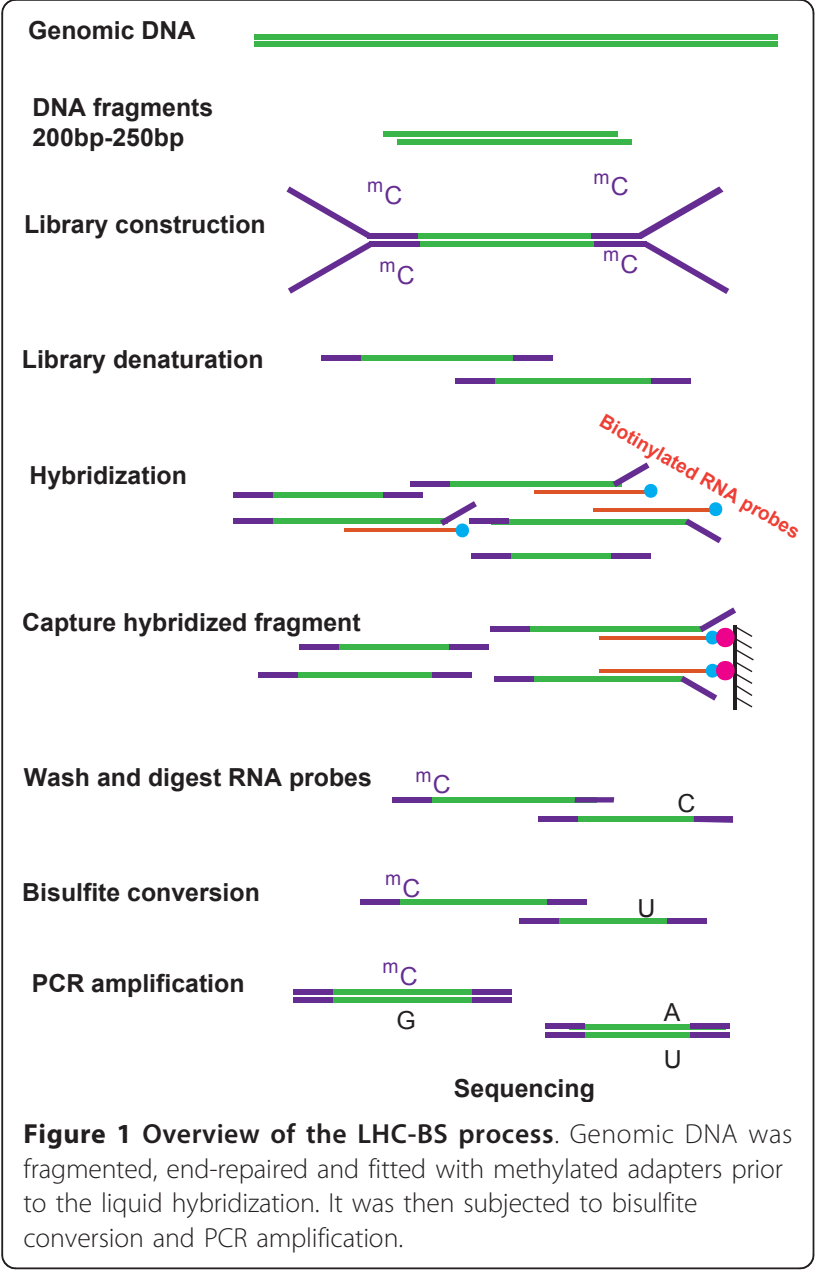

$\mathrm{YH}$ and $\mathrm{mDC}$ exomes, respectively. We found that more than $97 \%$ of the target exons were covered by unique reads in both samples. Of these, $90.21 \%$ and $89.16 \%$ of the regions were covered by at least 10 reads for each sample, respectively. Furthermore, $71.93 \%$ of the reads were enriched in the target regions for the $\mathrm{YH}$ blood sample, and $75.96 \%$ for the $\mathrm{mDC}$ cell line, thus indicating the high capture specificity of this assay for exome.

Because bisulfite conversion can result in allele dropouts at low DNA concentrations, we further evaluated the potential rate of allele loss for the $\mathrm{YH}$ sample by evaluating heterozygous SNPs (more than 2 alleles) (unpublished). Totally, 7172 heterozygous alleles were identified in the target regions with sequencing depths of more than $10 \times$ in $\mathrm{YH}$ whole genome bisulfite sequencing research, and 6992 of them were identified heterozygous by the current designed method. These results indicated that the rate of allele dropout was 2.5\% (Additional File 1 Table S2). The heterozygosity of A/G, C/T, G/A and $\mathrm{C} / \mathrm{T}$ was not included in this analysis because it was possible that they were generated during the bisulfite conversion.

\section{Accuracy of target exon capture}

Based on the massive sequencing reads that were uniquely mapped to the reference genome, we further examined the read distribution across the whole genome. As indicated in Figures $2 \mathrm{a}$ and $2 \mathrm{~b}$, the reads were distributed across all chromosomes, indicating the efficient coverage of the target regions. The average sequencing depth for each chromosome was over $30 \times$ for the negative strands in both the $\mathrm{YH}$ and $\mathrm{mDC}$ samples. To estimate the accuracy of target capture, we randomly isolated data from a specific region of the $D I P 2 B$ gene that is located on human chromosome 12 and used the Integrative Genomics Viewer (IGV) to assess the read distributions for both the $\mathrm{YH}$ and $\mathrm{mDC}$ samples. Using the IGV, we were able to determine that the profiles of the reads from the target region followed normal distributions, and most of them were enriched in the gene region (Figure 2c). These results verified the accuracy of this technique in the capture of target regions. The read distribution across chromosome 12 is presented in Additional File 2 Figure S1.

\section{Accuracy of methylation estimation of target regions}

To estimate the methylation statuses of the captured exon regions and evaluate the efficacy of LHC-BS in detecting genomic DNA methylation, methylation levels were assessed based on the following equation for one certain cytosine site: $\mathrm{mC}$ reads/ $\mathrm{C}$ reads $+\mathrm{mC}$ reads)* $100 \%$. Considering that not all unmethylated cytosines could be converted to thymine following the bisulfite treatment and because it is believed that nonCpG methylation is barely discernable in human somatic cells [26], we estimated the conversion rate by calculating the methylation levels of the non-CpG sites and adjusted the methylation levels of the CpG sites accordingly. We had previously performed WGBS on both samples and obtained sufficient data to evaluate the genomic methylation statuses (unpublished data), and we were thus able to apply these data to estimate the accuracies of the methylation measurements that were obtained using the LHC-BS method. We isolated WGBS reads that represented exon regions with at least nine-fold depths of coverage and performed correlation analyses with the LHC-BS reads from both samples. A correlation coefficient of 0.907 was obtained for the $\mathrm{YH}$ blood sample from the comparison of data of the two methods (Additional File 3 Figure S2 a). Similarly, a correlation coefficient of 0.925 was reached for the comparison with the $\mathrm{mDC}$ cell line (Additional File 3 Figure S2 b). Such high consistencies between the two sets of data that were generated by the two distinct methods are indicative of the accuracy of LHC-BS because WGBS is considered to be the gold standard for measuring methylation. 
(a)

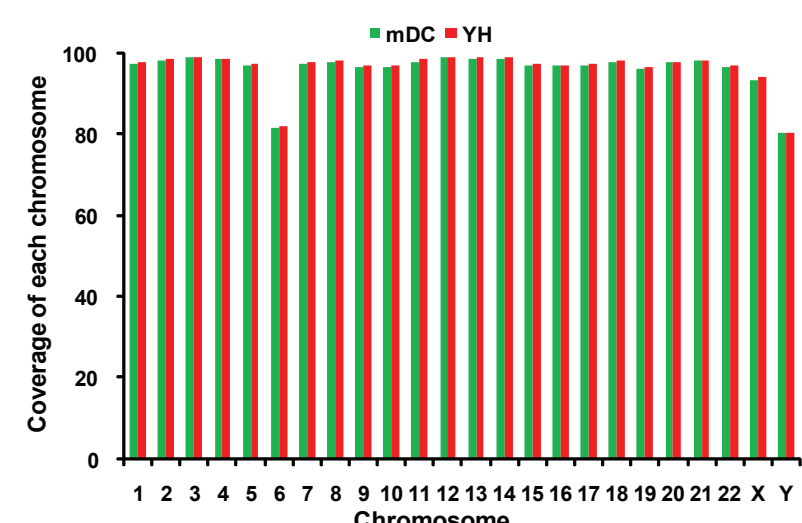

(b)

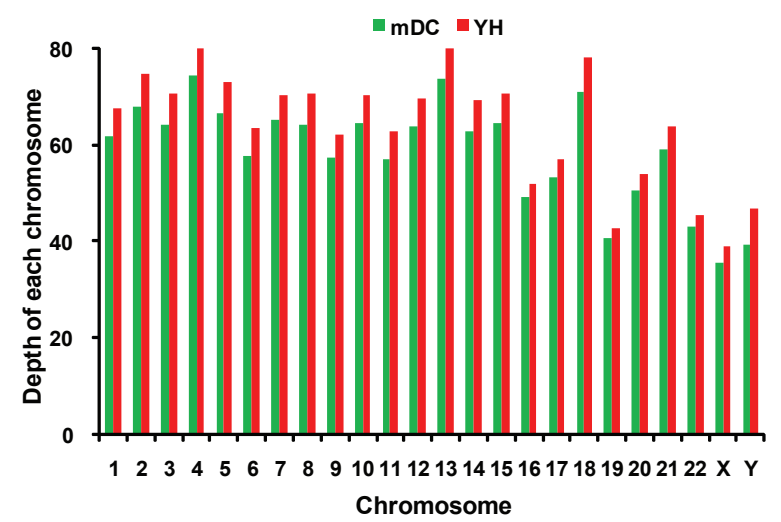

(c)

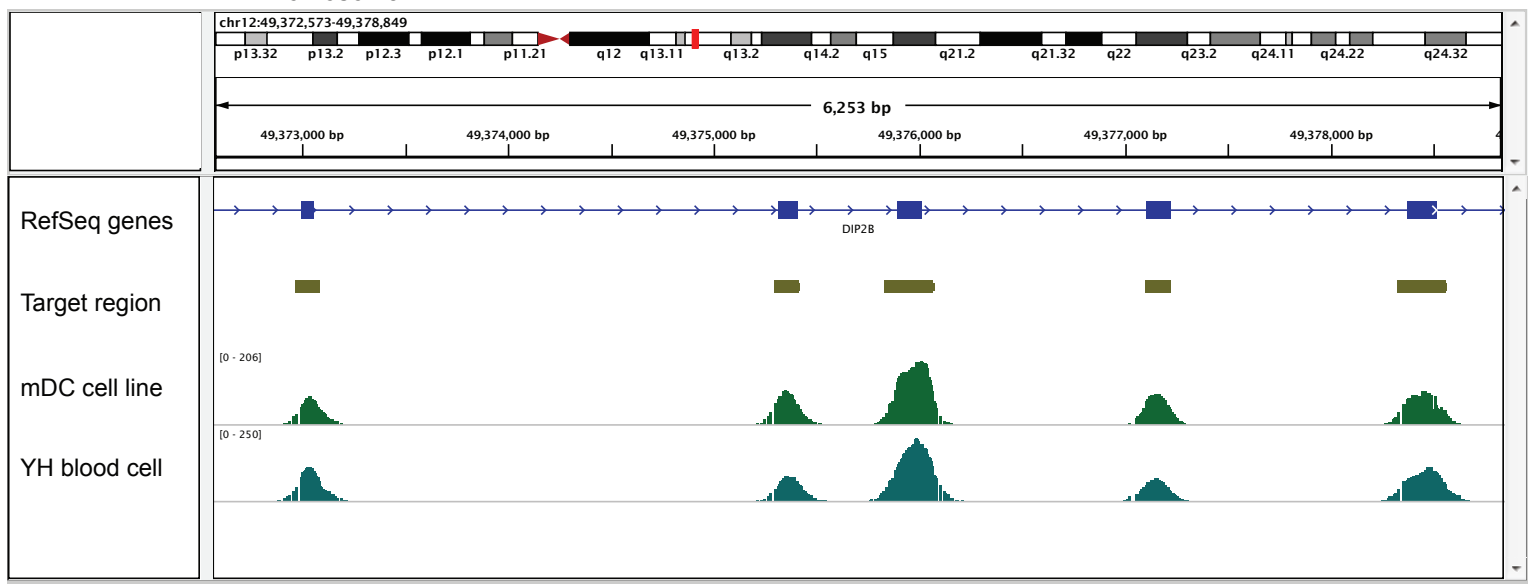

Figure 2 Accuracy of LHC-BS for determining the methylation statuses of specific regions. (a) The coverage of target regions (exons) from the $\mathrm{YH}$ and $\mathrm{mDC}$ genomes as captured by liquid hybridization using the LHC-BS platform that was based on uniquely mapped reads. (b) The sequencing depths of the exons that were captured from the $\mathrm{YH}$ and $\mathrm{mDC}$ genomic DNA. (c) Reads distributions that were derived from segments of the DIP2B gene originated from a portion of chromosome $12(49,372,573-49,378,849)$.

Secondly, we addressed the methylation levels in all gene regions of the $\mathrm{YH}$ blood sample and $\mathrm{mDC}$ cell line. As indicated in Figure 3, the methylation levels across the target gene regions were very similar between the two samples, suggesting similarities between the two cell types that are both primarily comprised of immunocytes. Due to these parallels, we were able to examine technological reproducibility to some extent; specifically, the average methylation level of all CpGs in the genomic regions around the TSSs was identified to be 3\%, which is consistent with the published results from the whole genome bisulfite sequencing of YH peripheral blood mononuclear cells [26].

To characterize the slight differences in the DNA methylation profiles between the samples, we performed pair-wise comparisons between the YH blood cells and $\mathrm{mDC}$ cell line. As expected, the results revealed that only 21 out of the 165637 targeted regions significantly differed between the two samples (see Methods), indicating highly similar DNA methylation profiles corresponding with the whole exon regions. A Gene Ontology (GO) analysis was employed to address the molecular functions of the genes from the 21 exon regions that exhibited significantly different DNA methylation patterns (Table 1).

\section{Validation of DNA methylation by BS-PCR}

Certain biases may be introduced during exome capture, thus hampering the accuracy of LHC-BS. To confirm the methylation events that were detected by LHC-BS, BS-PCR was performed on four randomly chosen genomic fragments. These fragments had low, moderate or high methylation levels in both the $\mathrm{YH}$ blood sample and $\mathrm{mDC}$ cell line, and there were 27 individual $\mathrm{CpG}$ sites in total. Fisher's tests were applied to verify statistical efficacy, and it was observed that none of the CpG sites presented with significant differences in DNA methylation levels when the LHC-BS and BS-PCR results were compared (Additional File 1 Table S3). For instance, a region that is located in the 5'UTR of the 


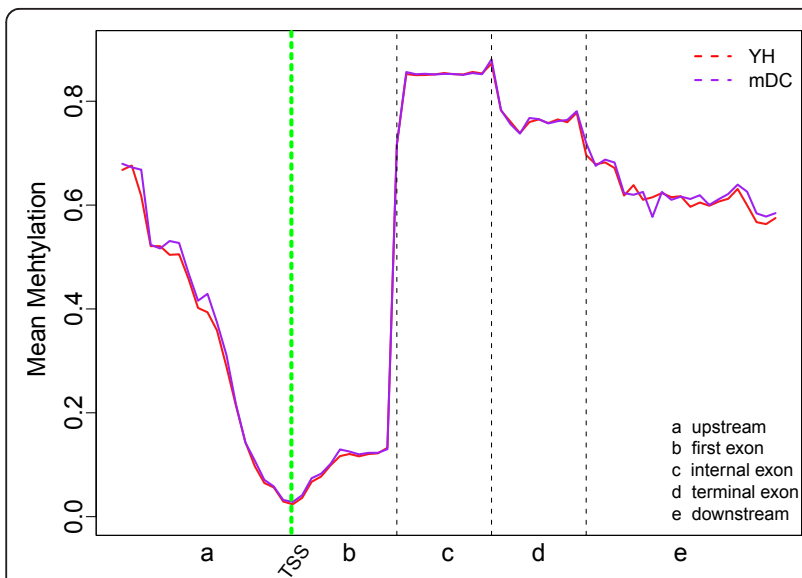

Figure 3 Mean methylation levels of CG distributions in target regions. The upstream region was defined as the $2 \mathrm{~kb}$ upstream of the TSS, and the downstream region was defined as the $2 \mathrm{~kb}$ downstream of the TTS. Data analysis results shown that

sequencing depths were observed increase in areas that were closer to gene regions. Each region of the two parts was divided equally into 20 sections. Moreover, the first, internal and terminal exons each shared 10 sections. Each methylation level that was reported represented the mean value of the corresponding section.

$M O B P$ gene was identified by LHC-BS to have moderate methylation levels of $9.80 \%$ and $22.37 \%$ in the $\mathrm{mDC}$ cell line and $\mathrm{YH}$ blood sample, respectively. Similar results were observed for the two samples following BS-PCR (Figure $4 \mathrm{a})$. In the other three verified regions, sequences from the DSPP gene presented with nearly undetectable methylation levels (Figure $4 \mathrm{~b}$ ), and the WDR37 and DIP2B genes were shown to be heavily methylated using both technologies (Figure $4 \mathrm{c}$ and $4 \mathrm{~d}$ ). Thus, taking into account the random selection of the DNA fragments for validation, we did not observe any bias in the detection of methylation levels using LHCBS.

\section{Discussion}

Along with the completion of various genome sequencing projects and more wide spread uses of highthroughput sequencing technologies, many strategies have been developed to assess DNA methylation that require the enrichment of specific genomic regions of interest. For example, microarray-based strategies utilized bisulfite-converted DNA to probe defined regions by the bimodal hybridization of either unconverted or converted probes [24]. This technique enables the detection of original methylation states at specific CpG sites, but it is difficult to design an adequate number of unique probes to extend this approach to a genomewide scale. However, Hodges et al. [25] recently modified this strategy and integrated it with deep sequencing.

Table 1 Top 21 Gene Ontology categories between the YH and the mDC samples

\begin{tabular}{|c|c|c|c|c|c|c|}
\hline $\begin{array}{l}\text { Gene } \\
\text { name }\end{array}$ & GO ID & NM & GO category & $\begin{array}{l}\text { Methylation level } \\
\text { of } \mathrm{mDC}\end{array}$ & $\begin{array}{l}\text { Methylation level } \\
\text { of } \mathrm{YH}\end{array}$ & $P$ value \\
\hline HELLS & GO:0005524 & NM_018063 & ATP binding & 33.333 & 1.316 & 4.54E-03 \\
\hline MSI1 & GO:0007399 & NM_002442 & nervous system development & 20.833 & 2.632 & 8.23E-03 \\
\hline CEBPE & GO:0046983 & NM_001805 & protein dimerization activity & 23.739 & 9.081 & $5.58 \mathrm{E}-79$ \\
\hline EML2 & GO:0007605 & NM_012155 & sensory perception of sound & 27.621 & 13.554 & 9.63E-12 \\
\hline GLTSCR2 & GO:0005634 & NM_015710 & nuclear & 23.36 & 11.579 & $1.52 \mathrm{E}-04$ \\
\hline TBC1D17 & GO:0005096 & NM_024682 & GTPase activator activity & 25.197 & 3.425 & $3.51 \mathrm{E}-14$ \\
\hline $\mathrm{BDH} 1$ & GO:0016491 & NM_203314 & oxidoreductase activity & 22.892 & 11.345 & $6.49 \mathrm{E}-13$ \\
\hline COL23A1 & GO:0016021 & NM_173465 & integral to membrane & 20.896 & 10.081 & $5.73 \mathrm{E}-03$ \\
\hline WASF1 & GO:0030041 & NM_001024936 & actin filament polymerization & 22.215 & 10.467 & $9.32 \mathrm{E}-23$ \\
\hline MYO1G & GO:0016459 & NM_033054 & myosin complex & 21.907 & 8.239 & $5.16 \mathrm{E}-13$ \\
\hline ARMCX2 & GO:0016021 & NM_014782 & integral to membrane & 31.395 & 14.286 & $5.12 \mathrm{E}-04$ \\
\hline MMP21 & GO:0008270 & NM_147191 & zinc ion binding & 9.375 & 33.862 & 1.05E-07 \\
\hline ITGA7 & GO:0016020 & NM_002206 & membrane & 10.879 & 21.88 & $1.39 \mathrm{E}-11$ \\
\hline DHRS12 & GO:0016491 & NM_024705 & oxidoreductase activity & 8.696 & 23.144 & $1.55 \mathrm{E}-05$ \\
\hline AURKC & GO:0016740 & NM_001015878 & transferase activity & 10.256 & 30.769 & $9.17 \mathrm{E}-03$ \\
\hline SOX18 & GO:0006357 & NM_018419 & $\begin{array}{l}\text { regulation of transcription from RNA polymerase } \\
\qquad \text { II promoter }\end{array}$ & 3.656 & 20.225 & $2.55 \mathrm{E}-15$ \\
\hline CIDEC & GO:0006917 & NM_022094 & induction of apoptosis & 8.333 & 20.098 & $6.22 \mathrm{E}-04$ \\
\hline PF4 & GO:0045653 & NM_002619 & $\begin{array}{l}\text { negative regulation of megakaryocyte } \\
\text { differentiation }\end{array}$ & 0 & 22.222 & $3.13 \mathrm{E}-03$ \\
\hline MARCKS & GO:0051015 & NM_002356 & actin filament binding & 5.405 & 30.088 & 4.66E-03 \\
\hline PRAF2 & GO:0016021 & NM_007213 & integral to membrane & 8.333 & 26.02 & $3.00 \mathrm{E}-03$ \\
\hline FAM155B & GO:0016021 & NM_015686 & integral to membrane & 0 & 21.053 & 4.02E-04 \\
\hline
\end{tabular}

The methylation level represents the average methylation level of the CpGs in the region. The $P$ value was calculated using the chi-square test. 


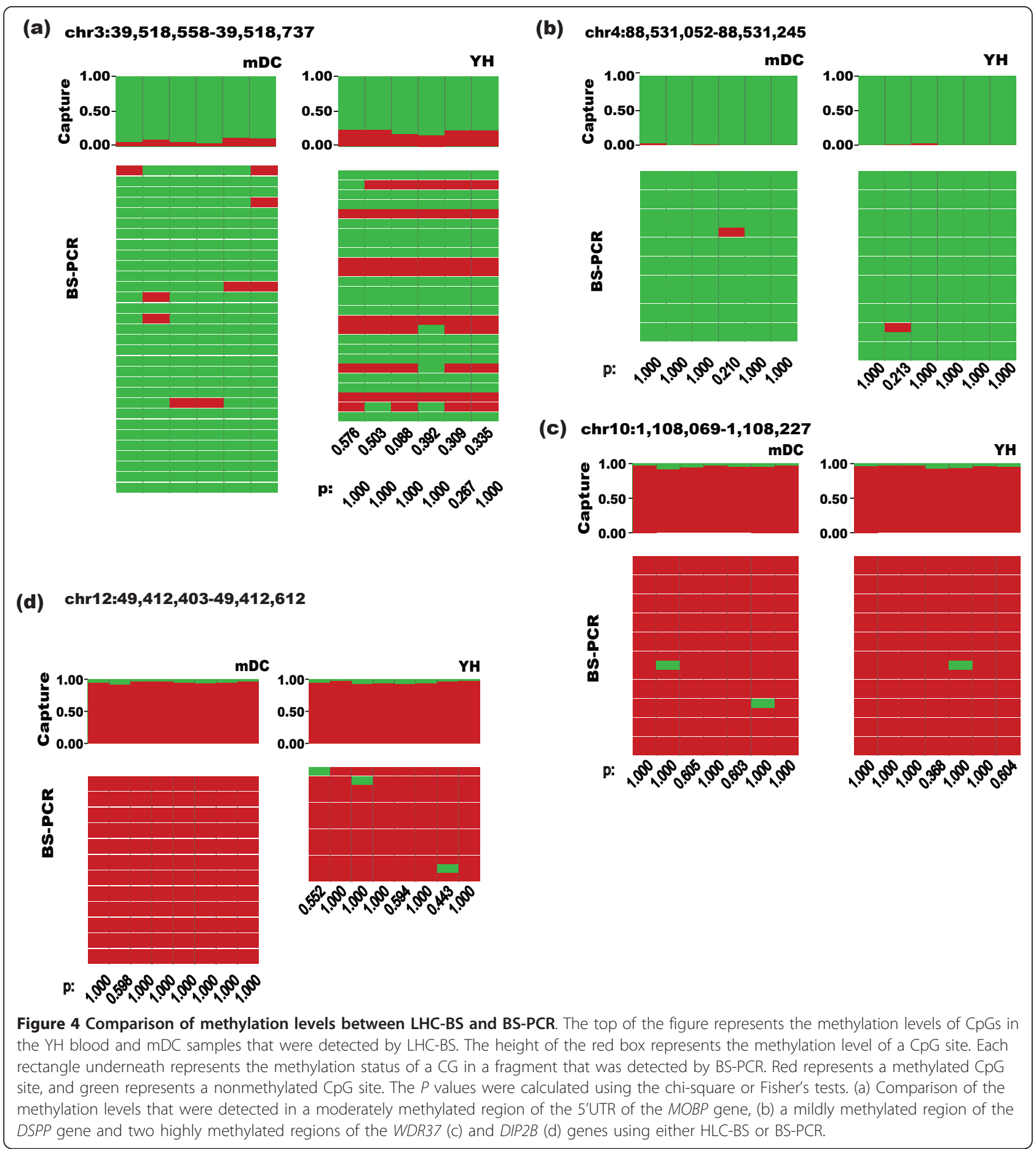

For each CpG island, they designed two sets of probes; one designed to detect no conversion at any of the $\mathrm{CpG}$ residues and another to distinguish the full conversion of CpGs to TpGs. They hypothesized that even with completely random $\mathrm{CpG}$ methylation patterns, only half of the CpG sites within a given probe would contribute a mismatch, and that was tolerated. However, the methods that were based on microarray hybridization enrichment were either laborious or required large volumes of DNA and were therefore not easily adapted to the massive screening of clinical samples. In the current study, we described a novel technique that combined sequence capture with bisulfite conversion and deep sequencing. In contrast to the strategy that Hodges 
et al. described [25], we utilized biotinylated RNA probes without bisulfite conversion to capture native genomic regions of interest. This adjustment in the experimental procedures allowed for a drastic decrease in the amount of DNA that was required for capture and more accurate measurements of methylation statuses. Previously, Hodges et al. used $20 \mu \mathrm{g}$ of PCRamplified genomic DNA for a microarray-based capture experiment. In contrast, $2-3 \mu \mathrm{g}$ of genomic DNA was used in the library construction for the present study, and $500 \mathrm{ng}$ of the constructed library was sufficient for the hybridization capture and subsequent bisulfite treatment. To protect the captured library, $200 \mathrm{ng}$ of sheared $\lambda$ DNA was added to act as carriers of the DNA that had been eluted from the liquid capture in the current bisulfite treatment process. Based on these modifications, we were not only able to facilitate the probe design process by not requiring any prior consideration of methylation sites but were also able to utilize small amounts of native, unamplified input DNA to examine the methylation statuses of specific regions by designing probes that covered different genomic regions.

Recent investigations involving DNA methylation within different gene regions showed that exons are disproportionately enriched in densely methylated genomic elements [21,26-29]. Hypermethylation that occurs downstream of the TSS and first exon is closely associated with transcriptional silencing, whereas methylation that occurs in the more downstream portions of the gene body is not $[26,29]$. In highly expressed genes, the promoter regions are hypomethylated while the rest of the gene-body regions are considerably methylated. However, weakly expressed genes are moderately methylated in both the promoter and gene-body regions. Thus, the function of intragenic DNA methylation is ambiguous. Previous research has indicated that intragenic DNA methylation, exonic nucleosomes and histone modifications may function together to regulate transcript splicing and gene expression [23,30,31].

Here, we profiled the human whole exome methylation statuses of two samples and obtained the same patterns as were previously detected using WGBS [26]. Using this set of probes, we covered $31 \%$ of the promoter regions and approximately $100 \%$ of the exons. Most of the regions that were not covered (Figure 2a) were distributed in chromosomes 6 and Y. Because we only calculated uniquely mapped reads, we determined that a large number of multiple mapping were present in the uncovered regions of chromosomes 6 and Y. For this reason, the data that was obtained using LHC-BS did not provide accurate methylation information for these regions (Additional File 1 Table S4). Additionally, to collect sufficient information, we generated massive amounts of data using excessive sequencing depths for the two samples, which reasonably led to the high duplication rate of $40.32 \%$ for the $\mathrm{YH}$ blood sample and $61.04 \%$ for the mDC cells. However, this value can be adjusted by reducing the amount of raw sequencing data in future studies. It has been reported that bisulfite conversion may result in allele dropouts at low DNA concentrations [32]. We calculated the allele loss rate to be $2.5 \%$, indicating efficient allele enrichment.

We applied a commercially available liquid hybridization system for exon capture, for which all of the probes were designed using the Watson strand of the human genome. Therefore, only information regarding the methylation of the Crick strand was obtained in this study. However, DNA methylation occurs primarily at CpG dinucleotides in mammalian genomes [1,2,33]. For each round of DNA replication, DNMT1 DNA methyltransferase, which has a preference for hemimethylated DNA, fills in the missing methylation sites on the newly synthesized strand [34-36]. Thus, the presence of symmetric CpG methylation was presumed for the two DNA strands composing each human chromosome. For non-CpG methylation, which plays an important role in maintaining the pluripotency of stem cells [11], we may design probes in future studies that cover the doublestranded regions of interest.

\section{Conclusions}

In the present study, we applied a liquid hybridisation capture system to enrich for specific genomic regions, which was combined with bisulfite sequencing to examine the methylation statuses of the human exome for the first time. Two different samples were profiled, and the methylation patterns of the exons were compared with methylation patterns that had been obtained using WGBS. These comparisons demonstrated the high accuracy of methylation estimation that is possible using this novel LHC-BS method. In contrast with the array-based capture strategy [25], we captured target regions without pre-converting genomic DNA using a bisulfite treatment. Instead, we used 2-3 $\mu$ g of genomic DNA to construct a library and $500 \mathrm{ng}$ of them was then subjected to target regions capture and a following bisulfite treatment. This modification improved the efficacy of this platform for methylation profiling, especially with regard to its cost-effective use in the analysis of multiple clinical samples for biomarker detection.

\section{Methods}

\section{Sample preparation and DNA library construction}

Two types of genomic DNA were isolated from a peripheral blood sample that was obtained from the same individual whose genome and methylome had been previously sequenced $(\mathrm{YH})[26,37]$ and from a mature human dendritic cell line (mDC). The total DNA from 
the peripheral blood sample was prepared using the QIAamp DNA Blood Mini Kit following the manufacturer's instructions, and the DNA from the mature human dendritic cells was isolated by proteinase $\mathrm{K}$ digestion and phenol/chloroform extraction.

Prior to the library construction, 2-3 $\mu$ g of genomic DNA from each sample was fragmented using a Covarias sonication system to mean sizes of approximately $200 \mathrm{bp}$. After fragmentation, libraries were constructed according to the Illumina Paired-End protocol. Briefly, the purified, randomly fragmented DNA was treated with a mix of T4 DNA polymerase, Klenow fragments, $\mathrm{T} 4$ polynucleotide kinase and a nucleotide triphosphate mix to repair the ends by blunting and phosphorylation. The blunted DNA fragments were subsequently 3 '-adenylated using the Klenow fragment ( $3^{\prime}-5^{\prime}$ exo-) and ligated by T4 DNA ligase to BGI-designed PE Index Adaptors that had been synthesized with 5'-methylcytosine in place of cytosine. After each step, the DNA was purified using the QIAquick PCR Purification Kit (Qiagen). The constructed libraries were stored at $-20^{\circ} \mathrm{C}$ until the next step of hybridization.

\section{Liquid hybridization-based exon capture}

The SureSelect Human All Exon 38 Mb Kit was used for the hybridization process. The probes nearly covered all of the exons that were annotated by the CCDS in September of 2008. The constructed libraries for the capture were quantified using the Quant-iT dsDNA HS Assay Kit with the Invitrogen Qubit fluorometer. Five hundred nanograms of each library at concentrations of $147 \mathrm{ng} / \mu \mathrm{l}$ were required for the hybridizations as described in the protocol for the SureSelect Target Enrichment System for an Illumina Paired-End Sequencing Library. The hybridizations were performed using a thermal cycler that was set at $65^{\circ} \mathrm{C}$ for 24 hours with the lid heated to $105^{\circ} \mathrm{C}$; then, Dynabeads ${ }^{\circledR} \mathrm{M}-280$ Streptavidin (Invitrogen) was used to capture the biotinylated RNA probes that had hybridized with the fragments of the target regions. Finally, the captured library samples were washed and purified for the bisulfite conversion.

\section{Bisulfite conversion and PCR amplification}

The bisulfite conversion of the captured exon DNA was performed according to the instructions for the ZYMO EZ DNA Methylation-Gold Kit ${ }^{\mathrm{TM}}$ with some modifications. A total of $200 \mathrm{ng}$ of fragmented $\lambda$ DNA were added to act as carriers for the elution products from the hybridization. After the samples were denatured and treated with sodium bisulfite, they were desulfonated, and the cytosine was converted to uracil. PCR was carried out in a final reaction volume of $50 \mu \mathrm{l}$ that included $10 \mu \mathrm{l}$ eluted bisulfite conversion products, $4 \mu \mathrm{l} 2.5 \mathrm{mM}$ dNTP, $5 \mu \mathrm{l} 10 \times$ buffer, $0.5 \mu$ l JumpStart ${ }^{\mathrm{TM}}$ Taq DNA
Polymerase, $2 \mu \mathrm{l}$ PCR primers and $28.5 \mu \mathrm{l}$ water. The thermal cycling program was as follows: $94^{\circ} \mathrm{C}$ for $1 \mathrm{~min}$, 18 cycles of $94^{\circ} \mathrm{C}$ for $10 \mathrm{~s}, 58^{\circ} \mathrm{C}$ for $30 \mathrm{~s}, 72^{\circ} \mathrm{C}$ for $30 \mathrm{~s}$ and a final $5 \mathrm{~min}$ incubation at $72^{\circ} \mathrm{C}$. The temperature was held at $12^{\circ} \mathrm{C}$ following the termination of the cycling program. PCR products that ranged in size from 200 to $400 \mathrm{bp}$ were selected and gel purified using the QIAquick Gel Extraction Kit (Qiagen). They were then analyzed by the Bioanalyser Analysis System (Agilent, Santa Clara, USA) and quantified using real time PCR. According to the real time PCR measurements, two PCR products of distinct samples were pooled on one lane and sequenced by the Illumina Hiseq2000 using 90 bp paired-end sequencing reads.

\section{Bisulfite sequencing of specific regions}

Specific regions of bisulfite-treated genomic DNA from each of the samples were PCR amplified, and the products were cloned and sequenced using conventional Sanger sequencing. Briefly, $500 \mathrm{ng}$ of genomic DNA from each sample were converted according to the ZYMO EZ DNA Methylation-Gold Kit ${ }^{\mathrm{TM}}$ manufacturer's instructions. PCR primers were designed using the online MethPrimer software http://www.urogene.org/ methprimer/index.html. The PCR primer information is listed in Additional File 1 Table S5. These primers were designed to recognize regions that lack $\mathrm{CpG}$ sites to avoid any amplification bias that may have occurred due to the differences between the methylated and unmethylated sequences. Thermal cycling was performed as follows: $94^{\circ} \mathrm{C}$ for $1 \mathrm{~min}, 30$ cycles of $94^{\circ} \mathrm{C}$ for $10 \mathrm{~s}, 58^{\circ} \mathrm{C}$ for $30 \mathrm{~s}, 72^{\circ} \mathrm{C}$ for $30 \mathrm{~s}$ and a final $5 \mathrm{~min}$ incubation at $72^{\circ} \mathrm{C}$. The temperature was held at $12^{\circ} \mathrm{C}$ following the termination of the cycling program. The PCR products were purified using the QIAquick Gel Extraction Kit (Qiagen). The purified PCR products were subcloned, and colonies from each region were sequenced using the 3730 Genetic Analyzer (Applied Biosystems) to assess the methylated cytosine levels.

\section{Bioinformatic analysis}

The captured fragments were sequenced using an Illumina Hiseq2000 sequencer that generated raw data in a $90 \mathrm{bp}$ paired-end Fastq format. The data were processed using the Illumina base-calling pipeline. Subsequently, all reads were aligned to the hg18 reference genome using the SOAP2.01 aligner [38]. Briefly, we used the human reference genome to derive the soap libraries for the assessment of the mapping results of the bisulfite treatment. In the mapping process, the seed of a read was $30 \mathrm{bp}$, and 2 mismatches were permitted. Only mismatches of $5 \mathrm{bp}$ were allowed in the total read. Methylcytosines were identified according to a previously published strategy [26]. To reduce any bias that resulted 
from the PCR amplification, we chose optimal reads that possessed fewer gaps and mismatches when more than one read was mapped to the same position. Additionally, we preferred the paired-end mapped reads. Methylation levels were calculated using the following formula for certain cytosine types: $\mathrm{mC}$ reads/( $\mathrm{C}$ reads $+\mathrm{mC}$ reads) " $100 \%$. Because not all of the unmethylated cytosines could be converted to uracils by the bisulfite treatment, we estimated the non-conversion rate using the methylation rate of non-CpG sites.

To validate the results of the LHC-BS, Pearson's correlation analysis were utilized to conduct pair-wise comparisons between datasets that were derived from the LHC-BS and WGBS assays. For the BS-PCR validation analysis, the BLAST algorithm was applied to align the sequences (expect value $=1 \mathrm{E}-10)$. The Fisher's test was used to statistically define the significances of the differences between the methylation information that was generated by LHC-BS and BS-PCR $(P$ value $<0.01)$.

Three parameters were applied to identify the differentially methylated regions between the $\mathrm{mDC}$ cell line and YH blood sample. First, we summed all of the methylated and unmethylated nucleotides in the CpG sites for each region of the two samples, respectively. The Fisher's test was used to analyze the methylation differences for each target region using a $P$ value $<0.01$. Second, we separated out the regions that showed over two-fold increases in methylation levels between samples. Third, considering the non-uniformity of the methylation levels, we selected regions with differences in methylation of over $20 \%$ between the two samples. The obtained differentially methylated regions were then examined using the BGI WEGO software to determine the functional information for their respective genes.

\section{Additional material}

Additional file 1: Supplementary Tables 1-5. Table S1: Data statistics of YH and mDC from HLC-BS. Table S2: Assessment of the dropout of alleles of heterozygous genes from the YH LHC-BS data. Table S3:

Statistics of the methylation statuses of 27 individual $\mathrm{CpG}$ sites that were analyzed by HLC-BS and BS-PCR. $P$ values were calculated using the chisquare or Fisher's tests. Table S4: Analysis of the undetected target region characteristics. Table S5: BS-PCR primer information.

Additional file 2: Figure S1 LHC-BS read distribution along chromosome 12.

Additional file 3: Figure S2 Comparison of methylation rates between WGBS and LHC-BS. (a) The Pearson's correlation coefficient from the YH blood sample was 0.907 , and the confidence interval was 0.902-0.912; (b) for the mDC cell line, the correlation coefficient was 0.925 , and the confidence interval was 0.921-0.928. The $y$-axis shows the methylation rate of a cytosine as determined by the whole genome sequencing of bisulfite-treated DNA, and the $x$-axis shows the methylation level as determined by HLC-BS. This analysis was restricted to cytosines with at least nine reads in both samples.

\section{Acknowledgements}

We are indebted to the faculty and staff of the Beijing Genomics Institute at Shenzhen, whose names were not included in the author list but who contributed to the large-scale sequencing of this work. This project is supported by a grant from the National High Technology Research and Development Program of China (863 Program, No. 2009AA022707) and Projects of International Cooperation and Exchanges NSFC (No. 30811130531).

\section{Authors' contributions}

$X Z, H J, J S$, and JW conceived and designed the present study; HL, JW, RW and JW performed the experiments; GJ analyzed the data; JW, FG, GJ, MW and $\mathrm{HJ}$ wrote the manuscript. All authors read and approved the final manuscript.

Received: 6 June 2011 Accepted: 8 December 2011

Published: 8 December 2011

\section{References}

1. Gama-Sosa MA, Slagel VA, Githens S, Kuo KC, Ehrlich M: Tissue-specific differences in DNA methylation in various mammals. Biochim Biophys Acta 1983, 740:212-219.

2. Bird A: DNA methylation patterns and epigenetic memory. Genes Dev 2002, 16:6-21.

3. $L i E$, Bestor $T H$, Jaenisch R: Targeted mutation of the DNA methyltransferase gene results in embryonic lethality. Cell 1992, 69:915-926.

4. Okano M, Bell DW, Haber DA, Li E: DNA methyltransferases Dnmt3a and Dnmt3b are essential for de novo methylation and mammalian development. Cell 1999, 99:247-257.

5. Reik W: Stability and flexibility of epigenetic gene regulation in mammalian development. Nature 2007, 447:425-432.

6. Heard $\mathrm{E}$, Disteche CM: Dosage compensation in mammals: fine-tuning the expression of the $X$ chromosome. Genes Dev 2006, 20:1848-1867.

7. Lippman Z, Gendrel AV, Black M, Vaughn MW, Dedhia N, Lavine K, Mittal V, May B, Carrington JC, Doerge RW, Colot V, Martienssen R: Role of transposable elements in heterochromatin and epigenetic control. Nature 2004, 430:471-476.

8. Robertson KD: DNA methylation and human disease. Nat Rev Genet 2005, 6:597-610.

9. Feinberg AP: Phenotypic plasticity and the epigenetics of human disease. Nature 2007, 447:433-440.

10. Bock C: Epigenetic biomarker development. Epigenetics 2009, 1:99-110.

11. Lister R, Pelizzola M, Dowen RH, Hawkins RD, Hon G, Tonti-Filippini J, Nery JR, Lee L, Ye Z, Ngo QM, Edsall L, Antosiewicz-Bourget J, Stewart R, Ruotti V, Millar AH, Thomson JA, Ren B, Ecker JR: Human DNA methylomes at base resolution show widespread epigenomic differences. Nature 2009, 462:315-322

12. Feng $S$, Zhang $X$, Chen Z, Merriman B, Haudenschild CD, Pradhan $S$, Nelson SF, Pellegrini M, Jacobsen SE: Shotgun bisulphite sequencing of the Arabidopsis genome reveals DNA methylation patterning. Nature 2008, 452:215-219.

13. Keshet I, Schlesinger Y, Farkash S, Rand E, Hecht M, Segal E, Pikarski E, Young RA, Niveleau A, Cedar H, Simon I: Evidence for an instructive mechanism of de novo methylation in cancer cells. Nat Genet 2006 38:149-153.

14. Jacinto FV, Ballestar E, Esteller M: Methyl-DNA immunoprecipitation (MeDIP): hunting down the DNA methylome. Biotechniques 2008, 44:35-43.

15. Serre $\mathrm{D}$, Lee $B H$, Ting AH: MBD-isolated Genome Sequencing provides a high-throughput and comprehensive survey of DNA methylation in the human genome. Nucleic Acids Res 2010, 38:391-399.

16. Li N, Ye M, Li Y, Yan Z, Butcher LM, Sun J, Han X, Chen Q, Zhang X, Wang J: Whole genome DNA methylation analysis based on high throughput sequencing technology. Methods 2010, 52:203-212.

17. Bock C, Brinkman AB, Müller $F$, Simmer $F$, Gu $H$, Jäger $N$, Gnirke $A$, Stunnenberg HG, Meissner A: Quantitative comparison of genome-wide DNA methylation mapping technologies. Nat Biotechnol 2010, 28:1106-1114 
18. Harris RA, Wang T, Coarfa C, Nagarajan RP, Hong C, Downey SL, Johnson BE, Fouse SD, Delaney A, Zhao Y, Olshen A, Ballinger T, Zhou X, Forsberg K, Gu J, Echipare L, O'Geen H, Lister R, Pelizzola M, Xi Y, Epstein CB, Bernstein BE, Hawkins RD, Ren B, Chung WY, Gu H, Bock C, Gnirke A, Zhang MQ, Haussler D, et al: Comparison of sequencing-based methods to profile DNA methylation and identification of monoallelic epigenetic modifications. Nat Biotechnol 2010, 28:1097-1105.

19. Meissner A, Gnirke A, Bell GW, Ramsahoye B, Jaenisch R: Reduced representation bisulfite sequencing for comparative high-resolution DNA methylation analysis. Nucleic Acids Res 2005, 33:5868-5877.

20. Smith ZD, Gu H, Bock C, Gnirke A, Meissner A: High-throughput bisulfite sequencing in mammalian genomes. Methods 2009, 48:226-232.

21. Ball MP, Li JB, Gao Y, Lee JH, Park IH, Xie B, Daley GQ, Church GM: Targeted and genome-scale strategies reveal gene-body methylation signatures in human cells. Nat Biotechnol 2009, 27:361-368.

22. Gu H, Bock C, Jäger N, Smith ZD, Tomazou E, Gnirke A, Lander ES, Meissner A: Genome-scale DNA methylation mapping of clinical samples at single-nucleotide resolution. Nat Methods 2010, 7:133-136.

23. Maunakea AK, Nagarajan RP, Bilenky M, Ballinger TJ, D'Souza C, Fouse SD, Johnson BE, Hong C, Nielsen C, Zhao Y, Turecki G, Delaney A, Varhol R, Thiessen N, Shchors K, Heine VM, Rowitch DH, Xing X, Fiore C, Schillebeeckx M, Jones SJ, Haussler D, Marra MA, Hirst M, Wang T, Costello JF: Conserved role of intragenic DNA methylation in regulating alternative promoters. Nature 2010, 466:253-257.

24. Beck S, Rakyan VK: The methylome: approaches for global DNA methylation profiling. Trends Genet 2008, 24:231-237.

25. Hodges E, Smith AD, Kendall J, Xuan Z, Ravi K, Rooks M, Zhang MQ, Ye K, Bhattacharjee A, Brizuela L, Wigler M, Hannon GJ, Hicks JB: High definition profiling of mammalian DNA methylation by array capture and single molecule bisulfite sequencing. Genome Res 2009, 19:1593-1605.

26. Li Y, Zhu J, Tian G, Li N, Li Q, Ye M, Zheng H, Yu J, Wu H, Sun J, Zhang $H$, Chen Q, Luo R, Chen M, He Y, Jin X, Zhang Q, Yu C, Zhou G, Sun J, Huang Y, Zheng H, Cao H, Zhou X, Guo S, Hu X, Li X, Kristiansen K, Bolund $\mathrm{L}, \mathrm{Xu}$ J, et al: The DNA methylome of human peripheral blood mononuclear cells. PLOS Biol 2010, 8:e1000533.

27. Hellman A, Chess A: Gene body-specific methylation on the active $\mathbf{X}$ chromosome. Science 2007, 315:1141-1143.

28. Suzuki MM, Bird A: DNA methylation landscapes: provocative insights from epigenomics. Nat Rev Genet 2008, 9:465-476.

29. Brenet $F$, Moh M, Funk P, Feierstein E, Viale AJ, Socci ND, Scandura JM: DNA methylation of the first exon is tightly linked to transcriptional silencing. PLoS One 2011, 6:e14524.

30. Chodavarapu RK, Feng S, Bernatavichute X, Chen PY, Stroud H, Yu Y, Hetzel JA, Kuo F, Kim J, Cokus SJ, Casero D, Bernal M, Huijser P, Clark AT, Krämer U, Merchant SS, Zhang X, Jacobsen SE, Pellegrini M: Relationship between nucleosome positioning and DNA methylation. Nature 2010, 466:388-392.

31. Choi JK: Contrasting chromatin organization of $\mathrm{CpG}$ islands and exons in the human genome. Genome Biol 2010, 11:R70.

32. Ito $\mathrm{Y}$, Koessler T, Ibrahim AE, Rai S, Vowler SL, Abu-Amero S, Silva AL, Maia AT, Huddleston JE, Uribe-Lewis $S$, Woodfine $K$, Jagodic M, Nativio R, Dunning A, Moore G, Klenova E, Bingham S, Pharoah PD, Brenton JD, Beck S, Sandhu MS, Murrell A: Somatically acquired hypomethylation of IGF2 in breast and colorectal cancer. Hum Mol Genet 2008, 17:2633-2643.

33. Jones PA: The DNA methylation paradox. Trends Genet 1999, 15:34-37.

34. Bestor $T H$, Ingram VM: Two DNA methyltransferases from murine erythroleukemia cells: purification, sequence specificity, and mode of interaction with DNA. Proc Natl Acad Sci USA 1983, 80:5559-5563.

35. Hermann A, Goyal R, Jeltsch A: The Dnmt1 DNA-(cytosine-C5)methyltransferase methylates DNA processively with high preference for hemimethylated target sites. J Biol Chem 2004, 279:48350-48359.

36. Wu SC, Zhang Y: Active DNA demethylation: many roads lead to Rome. Nat Rev Mol Cell Biol 2010, 11:607-620.

37. Li G, Ma L, Song C, Yang Z, Wang X, Huang H, Li Y, Li R, Zhang X, Yang H, Wang J, Wang J: The YH database: the first Asian diploid genome database. Nucleic Acids Res 2009, 37:D1025-1028.

38. Li R, Li Y, Kristiansen K, Wang J: SOAP: short oligonucleotide alignment program. Bioinformatics 2008, 24:713-714. doi:10.1186/1471-2164-12-597

Cite this article as: Wang et al: High resolution profiling of human exon methylation by liquid hybridization capture-based bisulfite sequencing. BMC Genomics 2011 12:597.

\section{Submit your next manuscript to BioMed Central and take full advantage of:}

- Convenient online submission

- Thorough peer review

- No space constraints or color figure charges

- Immediate publication on acceptance

- Inclusion in PubMed, CAS, Scopus and Google Scholar

- Research which is freely available for redistribution 